\title{
PERANCANGAN VIDEO DESTINASI WISATA KULON PROGO SEBAGAI PEMBENTUK CITY BRANDING DAERAH
}

\author{
Raden Hadapiningrani Kusumohendrarto ${ }^{1}$, Nofria Doni Fitri ${ }^{2}$ \\ ${ }^{1,2}$ Program Studi Desain Komunikasi Visual, STSRD VISI Indonesia \\ kusumohendrarto@gmail.com ${ }^{1}$,donifitri13@gmail.com ${ }^{2}$
}

\begin{abstract}
Abstrak
Keberadaan sebuah kota saat ini sangat dipengaruhi oleh city branding yang diangkat oleh kota tersebut, seperti yang dibawa oleh Kabupaten Kulon Progo berupa "the jewel of java" atau "permata dari pulau jawa". Namun citra obyek wisata dari branding Kabupaten Kulon Progo masih belum maksimal penggunaannya di tengah terpaan kemajuan teknologi media dan era internet yang mudah di akses pada saat ini terlebih adanya infrastruktur bandara baru Yogyakarta bernama YIA (Yogyakarta International Airport). Adanya kemajuan teknologi video dengan media kualitas $4 \mathrm{~K}$ (ultra high definition) serta kemudahan akses internet yang telah mendukung saat ini tengah dilirik dan dipergunakan untuk berbagai proses branding. Salah satunya sebagai pembentuk city branding daerah secara online pada kanal Youtube yang dapat menampilkan kualitas video $4 \mathrm{~K}$ dengan gambar tajam tampak nyata dan dapat diakses dimana saja. Perancangan ini akan menggunakan metode perancangan audio visual yang menghasilkan video 4K destinasi wisata Kulon Progo di kanal Youtube untuk meningkatkan minat wisatawan terhadap bandara baru YIA sehingga terangkat city branding daerah Kulon Progo.
\end{abstract}

Kata Kunci: city branding, Kulon Progo, video 4K, wisata, youtube

\begin{abstract}
The existence of a city is strongly influenced by the city branding itself such as the branding used by Kulon Progo Regency: "the jewel of java". However, the image of tourism object from the Kulon Progo Regency branding is still not maximally used, especially in the middle of easy to access technology development and environment such as the new Yogyakarta airport infrastructure called YIA (Yogyakarta International Airport). The existence of advanced video technology as $4 K$ (ultra high definition) quality media and easy internet access that already supported are currently being looked at and used for various branding processes, one purpose is to form regional city branding online on the Youtube channel which can display $4 \mathrm{~K}$ video quality with sharp images that look real and accessed from anywhere. This design will use an audiovisual design method to answer the problem of city branding of the Kulon Progo Regency tourism objects. With the $4 K$ video design of Kulon Progo tourist destinations on the Youtube channel, it hopes it could raise the city branding of tourists' interest in tourism objects in Kulon Progo towards YIA airport.
\end{abstract}

Keywords: city branding, Kulon Progo, tourism, video 4k, youtube 


\section{PENDAHULUAN}

Daerah Istimewa Yogyakarta (DIY) merupakan salah satu Provinsi di Indonesia yang terletak di pulau Jawa, dan salah satu kabupaten yang terletak di DIY ialah Kab. Kulon Progo. Terletak di sebelah barat Kota Yogyakarta, Kulon Progo memiliki potensi destinasi wisata alam perbukitan yang masih terjaga, pantai, serta adanya infrastruktur bandara baru YIA (Yogyakarta International Airport). Adanya infrastruktur baru berupa bandara di Kulon Progo sebagai pendukung penggerak pengembangan ekonomi daerah ini diharapkan dapat memberikan dampak positif bagi perekonomian masyarakat Kabupaten Kulon Progo. Kulon Progo memiliki city branding berupa "the Jewel of Java" atau "Permata dari Pulau Jawa", dimana Kulon Progo mencoba memposisikan diri untuk menjadi permata dari pulau jawa dengan adanya beragam potensi yang mampu bersaing dan bernilai tinggi. City Branding merupakan sebuah program dalam membangun identitas yang melekat pada suatu kota, dimana terdapat janji yang diberikan kepada orang maupun sekelompok orang yang berhubungan dengan potensi yang dimiliki kota tersebut (Swasty, 2016). Seperti yang telah dijelaskan pemerintah kabupaten Kulon Progo dalam website resmi, city branding Kulon Progo "the jewel of java" dilakukan agar Kulon Progo dapat terus berpacu dan mempersiapkan diri dalam menyambut berbagai mega proyek yang telah direncanakan (Pemerintah Kabupaten Kulon Progo, 2011).

Penggunaan media sosial pada era digital ini pun sudah biasa dijadikan sebagai media city branding daerah lewat video online pada kanal Youtube dan dirasa sangat efektif (Cholil, 2018). Seperti halnya kota Melbourne di Australia menggunakan kanal youtube dengan channel "Visit Melbourne" sebagai media pengenalan city branding kota ke pemirsa youtube mengenai beragam potensi yang dimiliki, salah satunya berupa pengenalan "Award Winning Wines in Melbourne's". Pengenalan City Branding dari kota Melbourne lewat video di atas dirasa mampu mewakili potensi kota Melbourne sehingga dapat menarik perhatian pemirsanya untuk mengunjungi potensi yang dimiliki. Youtube memberikan informasi melalui gambar bergerak atau video yang dapat memberikan kesan dan sensasi secara audio visual. Kelebihan dari media video yakni dapat memanipulasi waktu dan ruang sehingga penonton dapat diajak untuk melanglang buana kemana saja meskipun dibatasi oleh ruang (Uno \& Lamatenggo, 2011)

Pengembangan dari media sosial youtube pun berkembang mengikuti ragam kemajuan gadget terkini seperti smartphone dan smartTV yang mampu menyuguhkan tampilan video dengan kualitas $4 \mathrm{~K}$ (ultra high definition), tampilan visual video yang jernih, tampak nyata dan memuaskan penikmatnya. Perkembangan yang terjadi saat ini telah merubah kebutuhan penggunanya, yang semula hanya kebutuhan informasi kini bertambah menjadi terpuaskannya visual dalam menikmati kebutuhan informasi. Perubahan kemajuan teknologi yang terjadi saat ini dirasa belum dipergunakan secara maksimal oleh Kabupaten Kulon Progo dalam mengenalkan beragam potensi yang dimiliki, terlebih adanya sebutan The Jewel of Java yang melekat pada Kulon Progo. 
Dari segi pemerintah daerah Kulon Progo, pada kanal youtubenya saat ini, terlihat masih belum memperhatikan potensi video $4 \mathrm{~K}$ untuk dapat mendukung pengenalan potensi wisata yang dimilikinya, terlebih adanya bandara baru YIA yang terletak di Kulon Progo. Ketika tidak dilakukan pengenalan potensi wisata yang dimiliki Kulon Progo, maka bandara baru tersebut hanya akan menjadi tempat transit para wisatawan saja. Karena nama Kulon Progo kurang dikenal sebagai tempat destinasi wisata di provinsi Yogyakarta.

Penggunaan media video $4 \mathrm{~K}$ dipilih untuk menyesuaikan dengan kedekatan media saat ini terhadap penggunanya. Dimana karena adanya fasilitas menonton video $4 \mathrm{~K}$, perlahan penggunanya mulai merubah kebutuhan videonya, yang semula hanya kebutuhan informasi namun kini berubah menjadi kebutuhan kepuasan dalam menonton (tampak nyata) dengan video 4K. Didasarkan dengan latar belakang tersebut, perancang melihat perlu adanya sebuah adaptasi media pada potensi yang dimiliki oleh Kulon Progo. Adanya peningkatan kualitas media video $4 \mathrm{~K}$ dan kemudahan akses internet saat ini dapat digunakan sebagai pembentuk city branding Kulon Progo di kanal Youtube untuk mengenalkan beragam potensi yang dimiliki seperti destinasi tempat wisata dan infrastruktur bandara baru YIA. Tujuan dari perancangan video pada kanal Youtube ini diharapkan dapat mendukung keselarasan dari semangat city branding yang dibawa oleh Kulon Progo berupa The Jewel of Jawa.

\section{METODE PENELITIAN}

Metode yang dipakai dalam perancangan ini adalah metode perancangan video (audiovisual) berupa Pra-Produksi, Produksi, dan Pasca Produksi yang kemudian digunakan untuk menghasilkan video pembentuk city branding daerah terhadap pengenalan potensi yang dimiliki Kulon Progo berupa destinasi wisata dan bandara baru YIA.

Sedangkan untuk metode pengumpulan data dilakukan dengan pengamatan atau observasi tempat atau obyek yang diteliti. Menurut Bungin (2011) observasi atau pengamatan adalah kegiatan keseharian manusia dengan menggunakan panca indra seperti mata, mulut, dan kulit. Metode observasi adalah metode pengumpulan data yang digunakan untuk menghimpun data penelitian melalui pengamatan dan pengindraan secara langsung. Sehingga pengambilan video dokumentasi akan disesuaikan dengan waktu yang tepat dan baik, ini dilakukan agar dapat menghasilkan gambar yang baik secara pencahayaan dan sesuai dengan kaidah videografi.

\section{HASIL DAN PEMBAHASAN}

Berdasarkan hasil survei dan observasi yang telah dilakukan pada kanal Youtube dan wawancara dengan pengelola destinasi wisata Kabupaten Kulon Progo yakni masih sedikitnya konten video berkualitas $4 \mathrm{~K}$ atau Ultra HD 2160P yang mengenalkan potensi dari Kulon Progo. Pada video yang sudah ada baru menampilkan sedikit destinasi yang dimiliki Kulon Progo dan video tersebut masih belum diberikan sentuhan cinematic sensasi kepuasan menonton video. Sehingga video $4 \mathrm{~K}$ dari konten yang sudah ada belum dapat memberikan kesan suasana berlibur ataupun keinginan untuk mengunjungi destinasi di Kulon Progo. Hasil video yang sudah ada masih terlihat monoton, baik secara 
pengambilan gambar ataupun penyajiannya. Video berupa mengikuti seseorang berjalan dari awal hingga akhir video tanpa menggali lagi setiap sudut dari potensi tersebut, sedangkan audio yang digunakan kurang sesuai dengan video yang diambil. Sehingga video yang sudah ada dirasa masih belum dapat mewakili city branding Kulon Progo yang keindahan destinasi wisatanya masih dapat digali atau disusuri lebih menarik lagi.

Sedangkan hasil observasi dan wawancara yang telah dilakukan menyebutkan sejauh ini dari pihak pemerintah Kabupaten Kulon Progo khususnya Dinas Pariwisata masih belum mengemas destinasi wisata yang dimiliki secara menarik dan belum melirik penggunaan media video $4 \mathrm{~K}$ pada kanal Youtube sebagai media pendukung city branding Kulon Progo "The Jewel of Java", yang dimana saat ini penggunaan smartTV sudah mulai banyak digunakan serta adanya kemudahan akses internet. Indonesia menjadi negara dengan minat tinggi terhadap penggunaan smartTV, karena adanya peralihan penggunaan dari TV konvensional ke smart TV (Evandio, 2020)

\subsection{City Branding}

Seperti yang telah disebutkan oleh Tim Wesfix (2017), branding adalah sebuah cara untuk menyakinkan seseorang terhadap janji yang dimiliki oleh suatu brand atau merek dapat tertanam kedalam benak orang tersebut, hingga terselaraskannya sebuah janji terhadap rasa percaya (trust) yang telah diberikan dan terwujudnya janji yang telah diberikan oleh suatu brand. Penggunaan branding ini pun berkembang hingga terbentuknya daerah yang mulai sadar terhadap peranan penting dari pengemasan sebuah citra daerah atau sering disebut sebagai city branding. Adapun beberapa variabel pendukung dalam terbentuknya sebuah city branding:

a. Alam atau potensi natural yang dimiliki secara alamiah oleh suatu daerah dan setiap tempat. Setiap daerah memiliki potensi alam yang berbeda, seperti letak geografis, pantai, pegunungan, danau, gua, hutan, dll. Kulon Progo sendiri memiliki potensi natural atau alam yang sangat berbeda dengan beberapa kabupaten maupun kota dari Provinsi Yogyakarta, yaitu dengan adanya barisan perbukitan yang dapat dikunjungi pada bagian utara Kabupaten Kulon Progo dan adanya pantai pada bagian selatan.

Salah satu fenomena alam yang telah lama ada di Kulon Progo berupa batu tebing tinggi pada "Puncak Widosari" yang terjadi secara alamiah karena fenomena penciptaan alam. Kemudian adanya satu sumber air gunung yang sangat deras dan debit airnya mampu digunakan oleh masyarakat sekitar dan mengalir alami pada destinasi wisata "Air Terjun Grojogan Sewu", "Sungai Mudal", dan "Kedung Pedut". Sedangkan untuk potensi alam lain berupa "Goa Kiskendo", "Goa Kebon", dan hutan mangrove di pinggir pantai dengan nama "Mangrove Jembatan Api-api" dengan keindahan pemandangan tepi laut "Pantai MJAA".

b. Infrastruktur sendiri merupakan elemen daerah agar dapat menjadi daya tarik saat berkunjung. Salah satu infrastruktur terpenting yaitu adanya kemudahan akses oleh 
penggunanya saat berada di daerah tersebut, infrastruktur bisa berupa kondisi jalanan yang baik untuk transportasi darat, adanya terminal pemberhentian bus, stasiun, bandara, dan pelabuhan. Sarana transportasi tersebut dapat diakses dengan mudah untuk menjelajah atau dipergunakan selama berada pada daerah tersebut. Infrastruktur yang dimiliki oleh Kulon Progo adalah "Stasiun Wates", "Terminal Bus Wates", dan bandara baru "Yogyakarta International Airport".

c. Bangunan atau arsitektur merupakan sebuah penanda penting suatu daerah, bahkan perjalanan sejarah dari suatu daerah dapat terlihat dari adanya bangunan lama yang telah berdiri sejak puluhan atau ratusan tahun. Arsitektur sendiri merupakan sebuah penanda ciri khas yang dapat ditemukan secara berbeda di setiap daerah. Untuk arsitektur Kulon Progo yang paling menarik dan khas ialah adanya "Jembatan Bantar" sebagai penyambung para pendatang dari arah kota Yogya menuju Kulon Progo, dan arsitektur lain berupa "Patung Nyi Ageng Serang" di tengah persimpangan jalan utama Kulon Progo yang menjadi sosok penting untuk Kulon Progo. Kemudian adanya "Waduk Sermo" yang menjadi sumber ketersediaan air untuk warga dan pertanian di sekitarnya.

d. Potensi ekonomi atau suatu bentuk hasil usaha untuk meningkatkan perekonomian dari beberapa sumber yang dimiliki seperti adanya hasil bumi maupun hasil laut. Potensi ekonomi ini dapat menjadi sumber pembeda dari setiap daerah. Hasil bumi Kulon Progo yang masih identik terlihat hingga saat ini ialah perkebunan teh peninggalan belanda pada perbukitan bagian utara Kulon Progo, seperti "Kebun Teh Nlinggo". Sedangkan untuk hasil laut atau tepiannya berupa tambak udang di sekitar "Mangrove Jembatan Api-api" atau MJAA.

Pengemasan city branding saat ini pun mulai merambah dunia digital online pada social media, tidak luput kanal Youtube yang mampu menyajikan audio visual secara menarik dan terlihat nyata. Adanya beberapa variabel diatas yang menjadi potensi dari Kulon Progo dapat dikemas secara menarik lewat media video untuk diunggah pada kanal Youtube sebagai media pengenalan city branding "the jewel of java" dari Kulon Progo yang letaknya berdekatan dengan kota Yogyakarta.

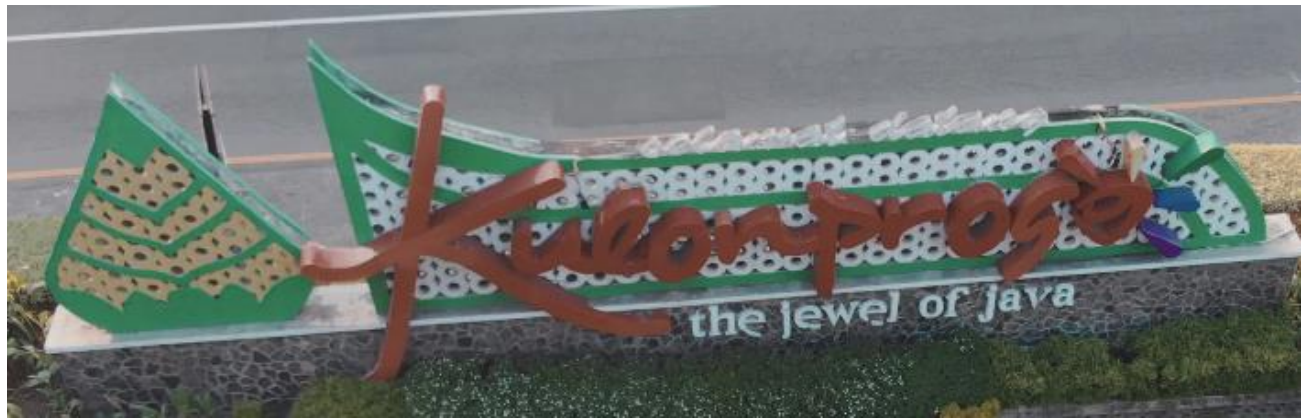

Gambar 1. Wall Display City Branding Kabupaten Kulon Progo

"Kulonprogo, the jewel of java"

[Sumber: Dokumentasi Penulis] 


\subsection{Ikon}

Merupakan sebuah tanda yang dapat mewakili suatu bentuk tertentu dan dapat dijadikan sebagai media pengingat terhadap kemiripan bentuk tersebut, berupa tanda visual, gambar, foto, maupun video yang menampilkan secara langsung suatu bentuk (Sari, 2014). Bentuk ikon yang dapat mewakili Kabupaten Kulon Progo adalah Patung Nyi Ageng Serang, Waduk Sermo, Jembatan Bantar Sungai Progo, Bandara baru YIA, dan tembok city branding "Kulonprogo the jewel of java" di dekat Jembatan Bantar sungai Progo.

\subsection{Perancangan}

Pada perancangan video 4K Kabupaten Kulon Progo ini akan dibuat dengan menampilkan beberapa variabel pendukung berupa destinasi wisata alam, wisata buatan, dan ikon dari Kulon Progo, sehingga secara tidak langsung dapat membentuk city branding Kulon Progo terhadap pengguna social media Youtube yang belum mengetahui ataupun baru sedikit mengetahui potensi dari Kulon Progo.

Tahapan dalam melakukan perancangan video $4 \mathrm{~K}$ destinasi Kulon Progo akan menggunakan tahapan seperti perancangan produksi film pada umumnya, berupa adanya tahap Pra-Produksi, Produksi, Pasca-Produksi. Sehingga adanya tahapan ini perancangan dapat dilakukan secara tersusun dan terevaluasi dengan baik sebelum video dapat disebarkan pada kanal Youtube.

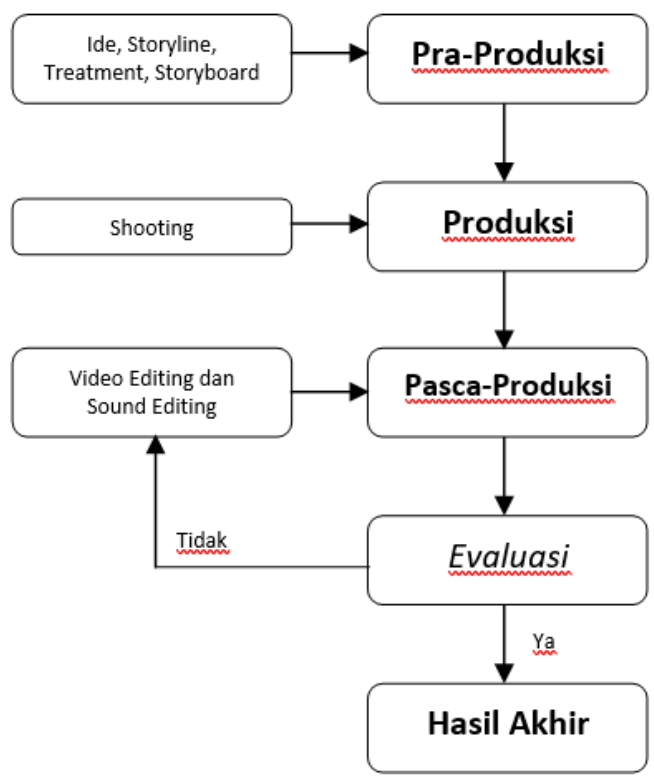

Gambar 3. Bagan Metode Produksi Film/Video

[Sumber: Dokumentasi Penulis]

\subsubsection{Pra Produksi}

City branding Kulon Progo "The Jewel of Java" merupakan ide utama dari perancangan video 4K yang akan diunggah pada kanal Youtube, sehingga hasil akhir video nanti akan menampilkan beberapa potensi destinasi wisata Kulon Progo yang dapat saling mendukung untuk pembentuk citra Kulon Progo nantinya. 
Storyline adalah sebuah rangkaian kajian, disusun menjadi cerita yang menarik dan dapat menyampaikan pesan dari ide utama. Maka storyline pada perancangan ini akan mencoba mengajak penonton video seperti seakan-akan berkunjung ke destinasi yang berada di Kulon Progo secara singkat dan cinematic. Sehingga penonton akan semakin terbawa ketika disajikannya dengan tampilan video yang berkualitas $4 \mathrm{~K}$ dan tampak nyata. Diawali dengan pengenalan bandara baru YIA, kemudian diberikan tampilan layaknya seseorang yang sedang berkendara menuju ikon Kulon Progo berupa Patung Nyi Ageng Serang dan setelahnya menuju destinasi wisata sekitar YIA yakni Kebun Teh Nglinggo yang masih tertutupi kabut di pagi hari, tidak jauh dari Kebun Teh Nglinggo terdapat puncak widosari yang memiliki batu tebing tinggi tanpa adanya campur tangan manusia. Selanjutnya penonton akan dikenalkan dengan adanya potensi wisata alam Goa Kiskendo yang masih terjaga bentuk stalakmit dan stalaktitnya, beranjak menuju Goa Kebon, wisata air di Waduk Sermo, air terjun Grojogan Sewu, Kedung Pedut, Sungai Mudal, Mangrove Jembatan Api-api, Pantai MJAA, Jembatan Bantar, dan diakhiri tembok display "Kulon Progo, The Jewel of Java". Keberadaan tempat-tempat tersebut akan diberikan teks pengenalan nama di setiap destinasi untuk menjelaskan saat ini berada dimana.

Tahap berikutnya berupa penyusunan treatment, dalam perancangan akan diberikan penjelasan berupa kerangka lengkap yang berisi penjelasan keterangan tempat dan durasi waktu. Pada treatment terdiri dari 16 scene sesuai storyline yang dibuat sebagai dasar penyusunan storyboard. Secara sederhana treatment dan storyboard dapat terlihat pada penjelasan storyboard berikut ini:

Tabel 1. Storyboard sebagai acuan penambilan video berdasarkan treatment [Sumber: Dokumentasi Penulis]

\begin{tabular}{|c|c|l|l|l|}
\hline Scene & \multicolumn{1}{|c|}{ Ilustrasi } & \multicolumn{1}{|c|}{ Shoot } & \multicolumn{1}{c|}{ Durasi } & \multicolumn{1}{c|}{ Keterangan } \\
\hline 1 & $\begin{array}{l}\text { Scene 1: } \\
\text { Long Shoot }\end{array}$ & 5 detik & $\begin{array}{l}\text { Pemandangan indah dari pinggir } \\
\text { bukit ke barisan perbukitan yang } \\
\text { tertutupi kabut }\end{array}$ \\
\hline 2 & & $\begin{array}{l}\text { Scene 2: } \\
\text { Medium } \\
\text { Shoot }\end{array}$ & 3 detik & $\begin{array}{l}\text { Jalanan masuk ke Bandara } \\
\text { Yogyakarta International Airport }\end{array}$ \\
\hline 3 & & Medium & 3 detik & $\begin{array}{l}\text { Patung selamat datang Bandara } \\
\text { Yogyakarta International Airport }\end{array}$ \\
& Shoot & & \\
\hline
\end{tabular}




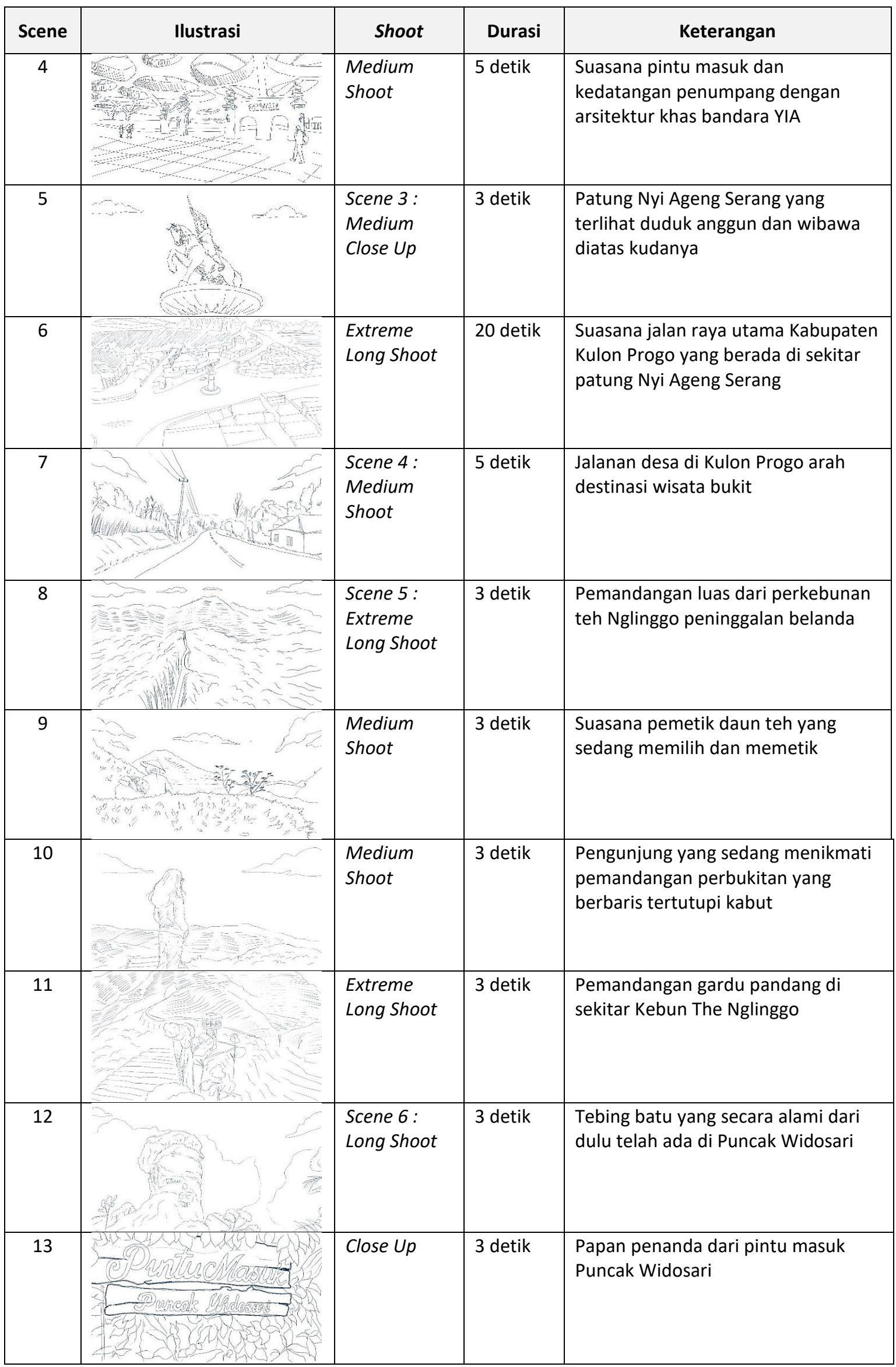




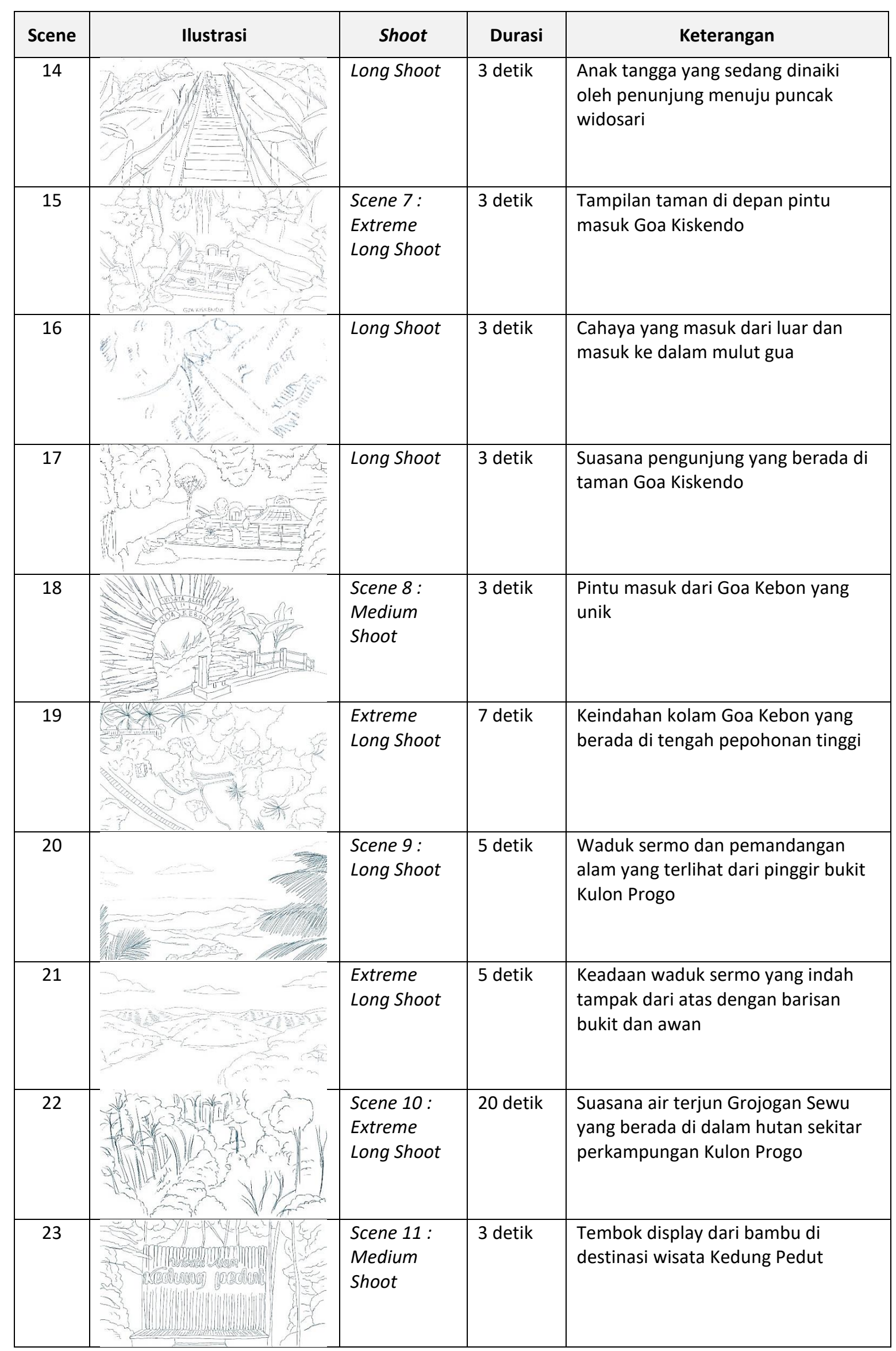




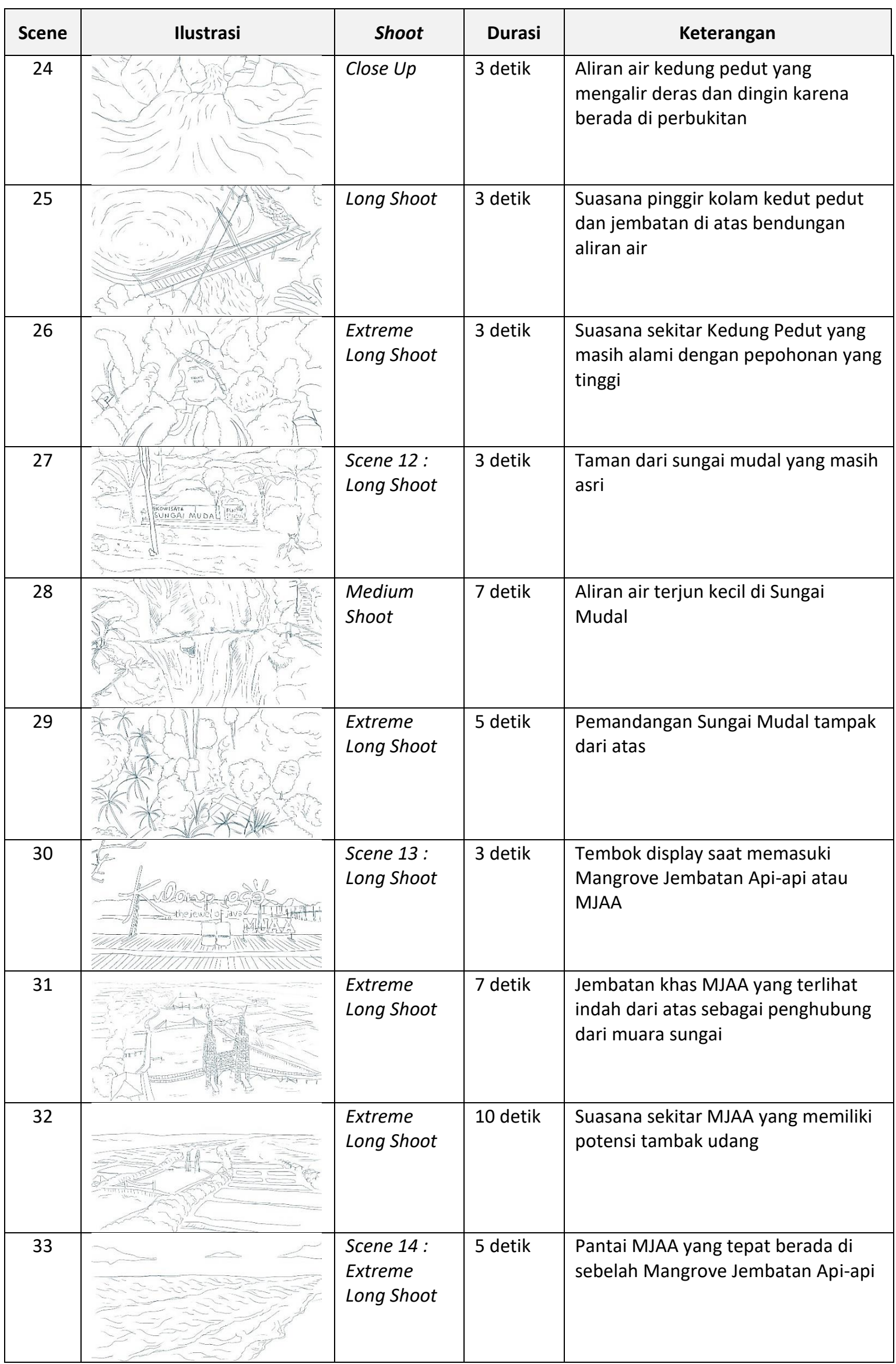




\begin{tabular}{|c|c|c|c|c|}
\hline Scene & Ilustrasi & Shoot & Durasi & Keterangan \\
\hline 34 & $(4) \times$ & Long Shoot & 3 detik & $\begin{array}{l}\text { Pinggiran pantai MJAA yang basah } \\
\text { terkena deburan ombak kecil }\end{array}$ \\
\hline 35 & $\operatorname{lin}_{2}$ & $\begin{array}{l}\text { Scene 15: } \\
\text { Extreme } \\
\text { Long Shoot }\end{array}$ & 3 detik & $\begin{array}{l}\text { Jembatan bantar sebagai } \\
\text { penghubung dari kota Yogya ke } \\
\text { Kabupaten Kulon Progo }\end{array}$ \\
\hline 36 & 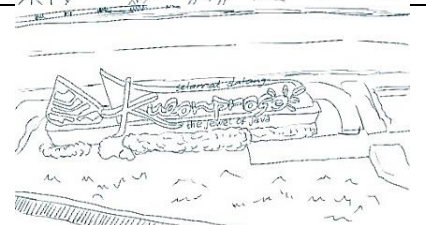 & $\begin{array}{l}\text { Scene 16: } \\
\text { Extreme } \\
\text { Long Shoot }\end{array}$ & 5 detik & $\begin{array}{l}\text { Tembok display Kabupaten Kulon } \\
\text { Progo, "The Jewel of Java" }\end{array}$ \\
\hline
\end{tabular}

\subsubsection{Produksi}

Tahap produksi merupakan tahap pengambilan gambar sesuai storyboard yang dilakukan untuk mengumpulkan bahan-bahan video sesuai dengan scene yang telah dilakukan di awal Pra Produksi. Waktu perekaman gambar dilakukan pada pagi hari dan sore hari untuk mendapatkan suasana dan warna destinasi wisata yang sangat beragam karena cahaya matahari berada di samping obyek berdiri bukan berada di atas obyek, sehingga mampu memberikan kesan menawan pada video terlebih untuk wisata alam. Pemilihan waktu perekaman menghindari pada siang hari karena memiliki kontras pencahayaan yang sangat tinggi dan tidak dapat memberikan kesan estetis pada video. Perekaman luar ruangan ini sangat bergantung pada situasi cuaca yang tidak dapat diprediksi, sehingga akan sangat bergantung pada pencahayaan matahari dan menghindari cuaca gelap atau sangat mendung.

Peralatan yang digunakan dalam proses perekaman gambar bergerak atau video ini akan menggunakan peralatan yang sudah mampu merekam video dengan resolusi $4 \mathrm{~K}$ sehingga video dapat menampilkan sebuah gambar yang tampak halus dan nyata, tidak menampilkan kualitas yang pecah ketika video berukuran kecil. Perekaman akan menggunakan alat yang menyesuaikan kebutuhan dalam mengambil gambar atau video berupa drone camera untuk dapat mengambil gambar dari tampak atas sehingga dapat menampilkan suasana destinasi wisata secara keseluruhan dan adanya sensasi pengalaman estetis melihat alam dari ketinggian, hingga mampu melihat secara detail dari sudut-sudut objek wisata pada Kulon Progo yang dimana penggunaan drone ini tidak dapat dilakukan oleh camera in hand. Adapun penggunaan mirrorless camera untuk memberikan kesan tampak nyata atau langsung, karena sejajar mata manusia memandang. Peralatan perekaman lainnya berupa action camera untuk memberikan kesan kepada penonton video seperti sedang mengamati atau mengamati perjalanan wisata. Perekaman video ini memiliki ukuran resolusi dengan kualitas $4 \mathrm{~K}$ atau Ultra High Definition yang memiliki ukuran 3840 × 2160 piksel serta memiliki kerapatan gambar dan jumlah piksel 4 kali lebih banyak dari ukuran Full HD 1920 × 1080 piksel. 
Selanjutnya dilakukan pengelompokan file video yang telah diambil berdasarkan scene dibuat agar pengerjaan saat pasca produksi dapat terpilih dan digunakan secara teratur dan baik, sehingga tidak terjadi kebingungan saat menyusun dan proses pengolahan video.

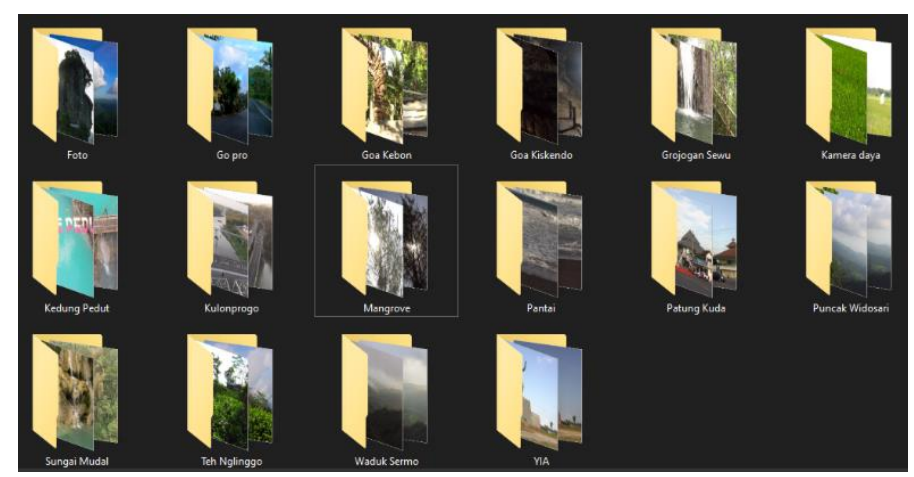

Gambar 2. Hasil pengelompokan video berdasarkan tempat destinasi wisata Kulon Progo

[Sumber : Dokumentasi Penulis]

\subsubsection{Pasca Produksi}

Merupakan sebuah proses lanjutan dari tahap Produksi untuk mengolah pengambilan video yang telah dilakukan sebelumnya. Pasca Produksi digunakan untuk mengolah video berdasarkan scene yang telah diambil untuk digabungkan dan mengolah warna video secara sinematik. Berikut hasil video editing yang telah dilakukan:
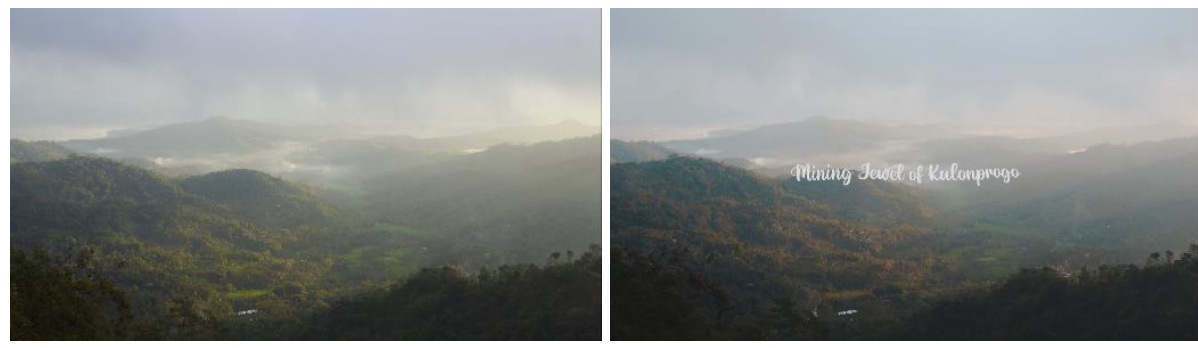

Gambar 3. Pengolahan warna dan penambahan teks di setiap destinasi wisata Kulon Progo [Sumber: Dokumentasi Penulis]

Pengolahan warna diberikan tampak hangat atau warm pada video untuk memberikan kesan dramatis kepada penonton sehingga seakan-akan penonton dapat merasakan kesan berwisata secara tidak langsung pada Kulon Progo. Sedangkan untuk judul perancangan video yakni "Mining Jewel of Kulonprogo" dengan arti menggali permata Kulon Progo yang memiliki beragam potensi destinasi wisata. Sehingga perancangan video $4 \mathrm{~K}$ di kanal Youtube ini dapat menjadi cara dalam mengenalkan city branding Kulon Progo yang memiliki destinasi wisata yang indah seperti yang tertuang ke dalam tagline "The Jewel of Java".

\subsection{Hasil Perancangan Video}

Setelah tahap Pasca Produksi yang sudah dilakukan pengolahan gambar video, penggabungan, dan rendering, maka hasil dari perancangan video ini akan menjadi 
sebuah video utuh yang dapat ditonton secara baik. Hasil produksi video ini berupa pengenalan beberapa destinasi wisata dan bandara baru YIA di Kabupaten Kulon Progo yang lokasinya tidak berjauhan. Konsep dari perancangan inipun berupa durasi video yang tidak terlalu panjang namun dapat secara jelas menyajikan dan mengenalkan potensi dari Kulon Progo. Video dibuat seakan-akan penonton adalah wisatawan yang berkunjung di Kulon Progo. Berikut ini adalah hasil dari perancangan yang telah dilakukan :

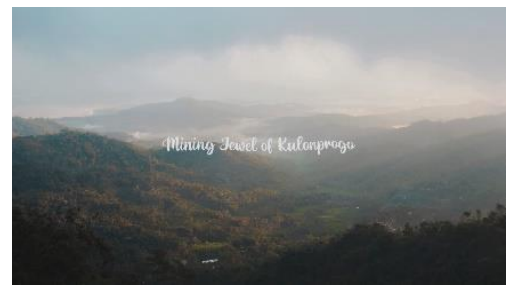

Gambar 4. Scene 1 (opening) [Sumber: Dokumentasi Penulis]

Hasil pada scene 1 ini merupakan scene opening yang mencoba menampilkan kelebihan yang dimiliki oleh kabupaten Kulon Progo berupa keindahan perbukitan berbaris yang tertutupi oleh kabut yang disambut dengan keindahan cahaya mentari pagi.
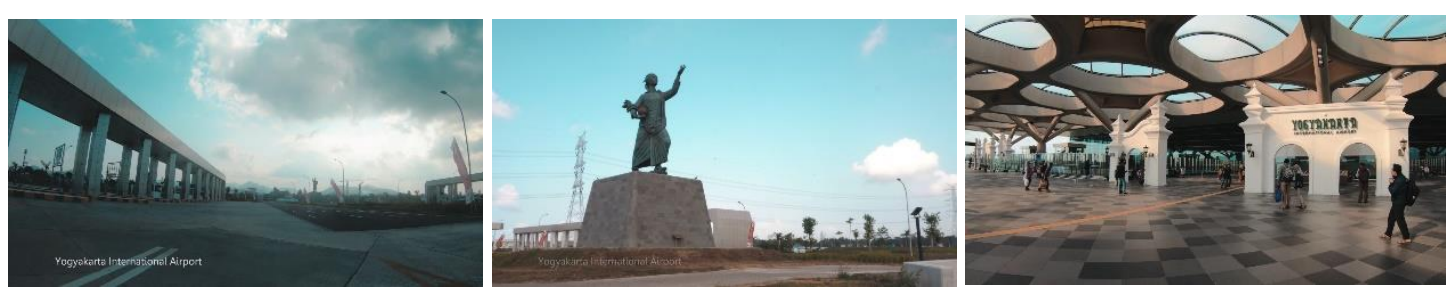

Gambar 5. Scene 2, Bandara baru Yogyakarta International Airport [Sumber: Dokumentasi Penulis]

Pada scene 2 mengambil tempat bandara baru Yogyakarta International Airport yang merupakan infrastuktur baru di Kulon Progo yang masih perlu diperkenalkan kepada wisatawan yang menggunakan transportasi udara. Sehingga pada scene ini menampilkan YIA sebagai dengan menggunakan sudut pandang seorang wisatawan.
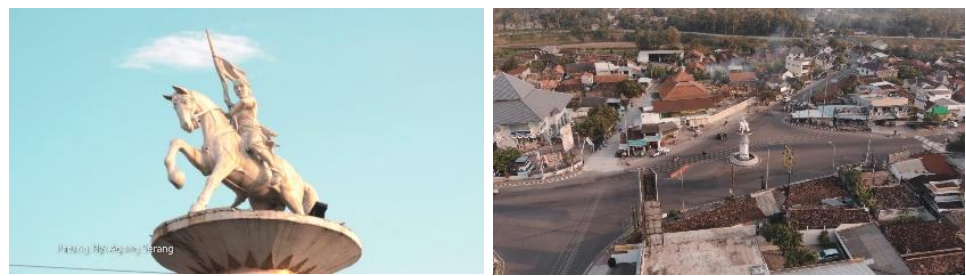

Gambar 6. Scene 3, Patung Nyi Ageng Serang [Sumber: Dokumentasi Penulis]

Selanjutnya pada scene 3 menampilkan Patung Nyi Ageng Serang yang menjadi sebuah ikon dari Kabupaten Kulon Progo yang dimana terletak di tengah persimpangan jalan wates sehingga hampir setiap orang yang melewati jalan utama Kulon Progo akan 
melihat patung tersebut. Pengambilan gambar dibuat terlihat lebih menarik dari atas agar dapat memberikan kesan yang berbeda terhadap penonton yang melihat.

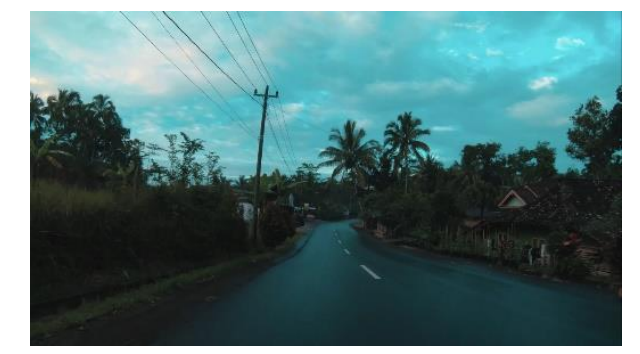

Gambar 7. Scene 4, Jalanan desa di Kulon Progo [Sumber: Dokumentasi Penulis]

Kabupaten Kulon Progo merupakan bagian dari Provinsi DIY yang masih memiliki suasana pedesaan di perbukitan yang asri, sehingga ketika seseorang berkunjung akan merasakan adanya suasana desa yang ramah. Sehingga pemilihan jalanan desa agar memberikan suasana kenyamanan untuk penontonnya.

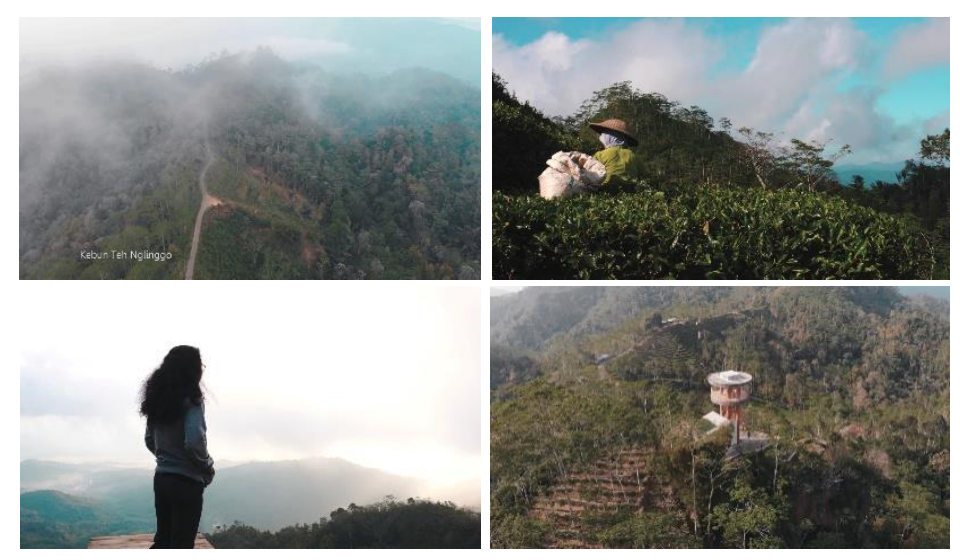

Gambar 8. Scene 5, Kebun The Nglinggo

[Sumber: Dokumentasi Penulis]

Berkunjung ke Yogyakarta tentunya akan menemukan keelokan warisan budaya yang masih terjaga dan terlestarikan, namun pada Kulon Progo kita dapat menemukan kebun teh yang masih dipergunakan dan terawat hingga saat ini, sehingga pada scene 5 diperlihatkan salah satu potensi yang menjadi daya tarik dari Kulon Progo dengan kondisi yang terselimutinya kabut dan munculnya cahaya matahari.
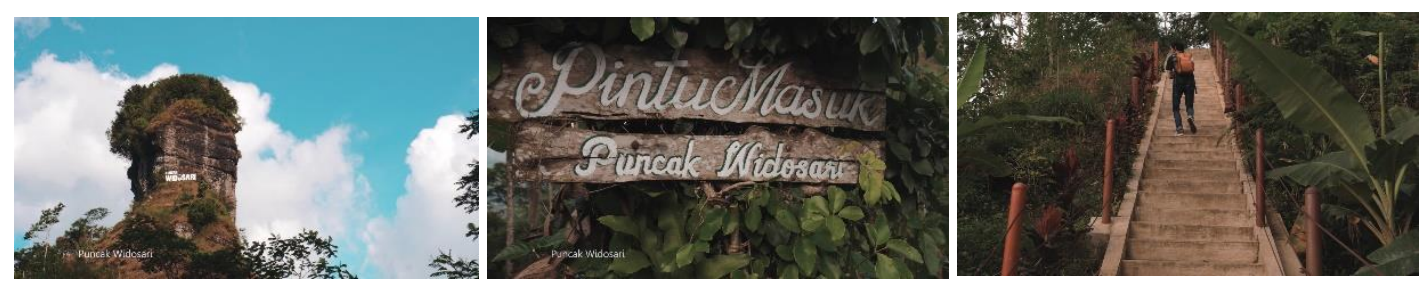

Gambar 9. Scene 6, Puncak Widosari

[Sumber: Dokumentasi Penulis] 
Tidak jauh dari Kebun Teh Nglinggo terdapat sebuah tebing batu yang memiliki hutan kecil di atasnya, serta menjulang tinggi di atas permukaan bukit yang terjadi secara alami tanpa campur tangan manusia. Sehingga pada scene 6 ini diperlihatkan sebuah potensi yang utama lainnya dari Kulon Progo yakni Puncak Widosari yang keindahannya masih alami terjaga.
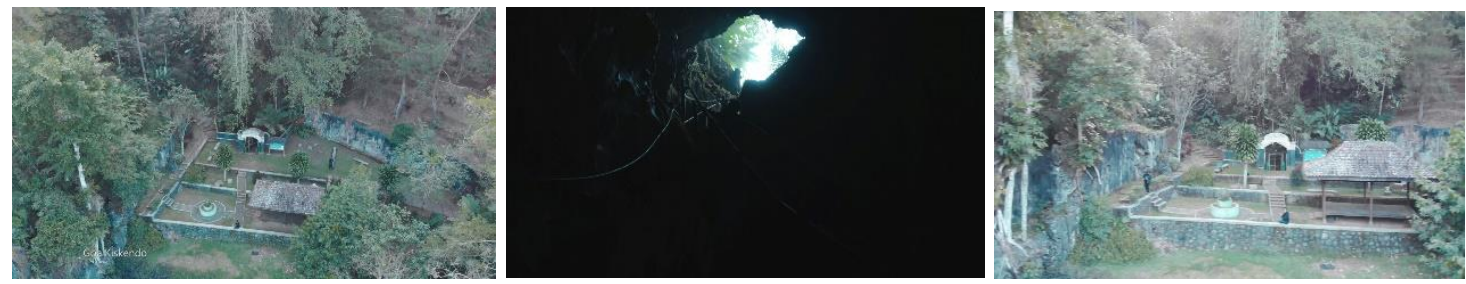

Gambar 10. Scene 7, Goa Kiskendo [Sumber: Dokumentasi Penulis]

Keberadaan wisata alam lain yang masih terjaga hingga saat ini adalah Goa Kiskendo, pemilihan tempat wisata ini digunakan sebagai tempat pengenalan adanya tempat belajar ilmu pengetahuan alam seperti stalaktit dan stalakmit di dalam gua. Sehingga Goa Kiskendo menjadi destinasi wisata yang wajib dimasukkan kedalam perancangan untuk menarik perhatian penonton agar berkunjung. Pengambilan gambar secara long shoot agar penonton dapat melihat secara jelas keadaan Goa Kiskendo.
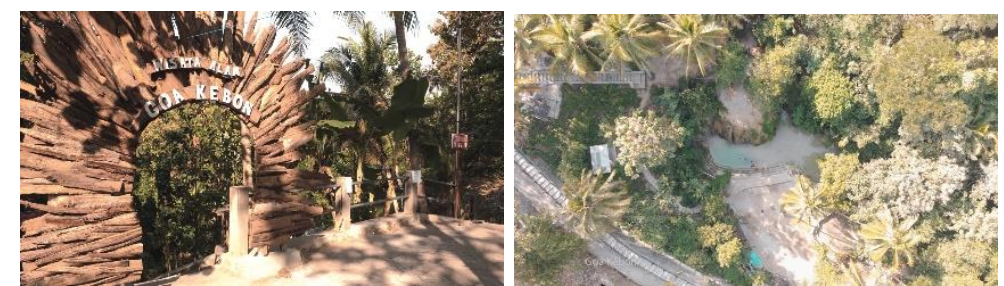

Gambar 11. Scene 8, Goa Kebon [Sumber: Dokumentasi Penulis]

Berada pada scene 8, pemilihan Goa Kebon menjadi daya Tarik lain dari Kulon Progo karena terdapatnya sebuah aliran air terjun yang di bagian bawahnya terdapat mulut gua sehingga banyak pengunjung yang tertarik untuk datang. Diperlihatkan tampak depan Goa Kebon dan tampak dari atas untuk memberi kesan alam yang terjaga.
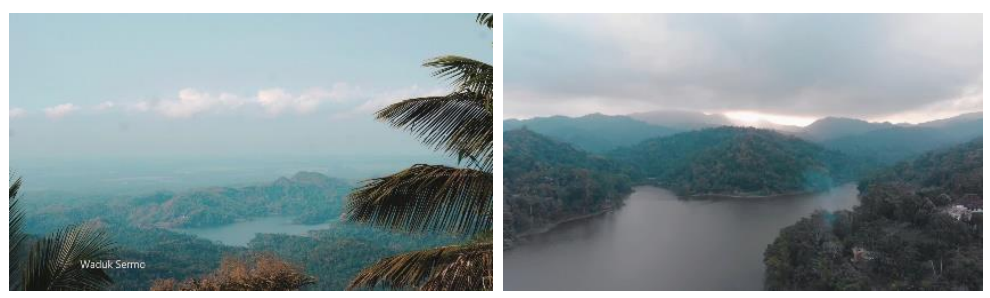

Gambar 12. Scene 9, Waduk Sermo

[Sumber: Dokumentasi Penulis] 
Waduk Sermo merupakan ciri khas wisata yang dimiliki oleh Kulon Progo, untuk menampilkan kealamiannya maka diambil dengan pengambilan gambar secara extreme long shoot.

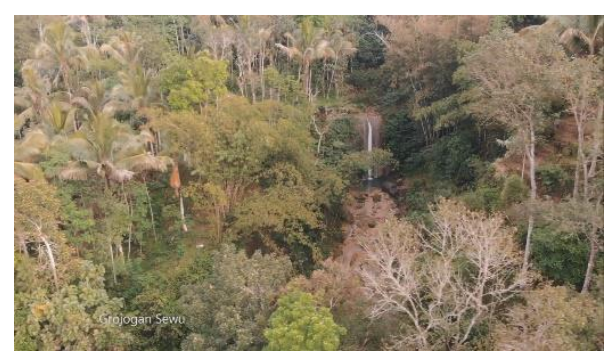

Gambar 13. Scene 10, Air Terjun Grojogan Sewu

[Sumber: Dokumentasi Penulis]

Adanya beragam keindahan destinasi yang dimiliki Kulon Progo, salah satunya ialah sumber mata air yang dapat mengaliri beberapa destinasi air terjun di beberapa sudut Kulon Progo. Scene 10 ini menjadi scene yang menjelaskan keindahan beberapa air terjun di Kulon Progo yang masih alami di tengah hutan, sehingga pemilihan extreme long shoot adalah pilihan yang tepat.
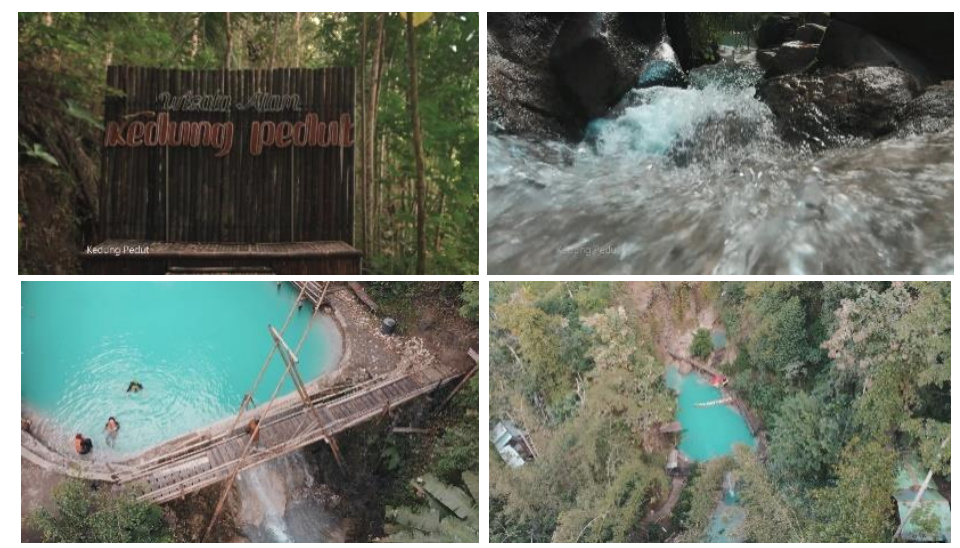

Gambar 14. Scene 11, Kedung Pedut [Sumber: Dokumentasi Penulis]

Scene 11 disini dipilih Kedung Pedut karena destinasi kedung pedut mampu memberikan kesan yang menarik dari aliran air terjun yang terbendung menjadi kolam untuk berenang. Karena air terjun di Kulon Progo mengandung kapur, maka sewaktu di bendung air akan terlihat berwarna biru. Pemilihan gambar aliran air untuk memberikan kesan segar.
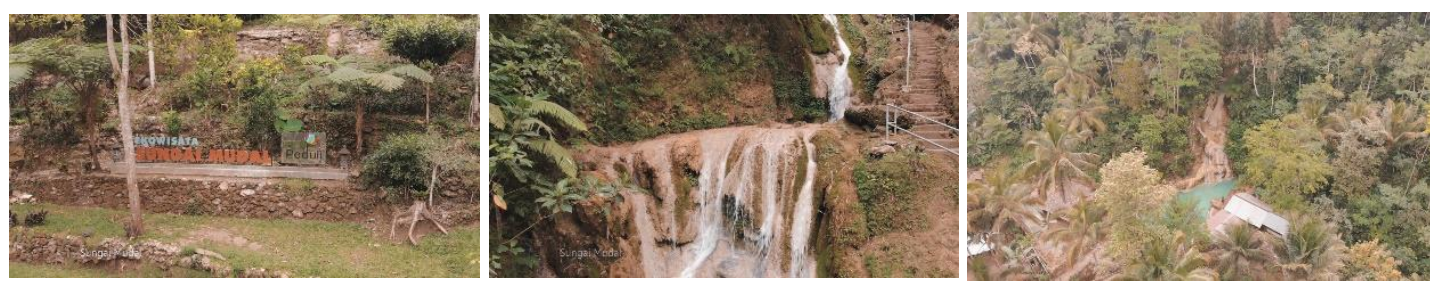

Gambar 15. Scene 12, Sungai Mudal

[Sumber: Dokumentasi Penulis] 
Destinasi wisata air terjun lain yakni Sungai Mudal, dipilih ditempatkan pada scene 12 untuk memberikan kesan bahwa Kulon Progo memiliki wisata air terjun yang terdapat di beberapa tempat. Pemilihan extreme long shoot adalah cara yang terbaik untuk menggambarkan keindahan Sungai Mudal.
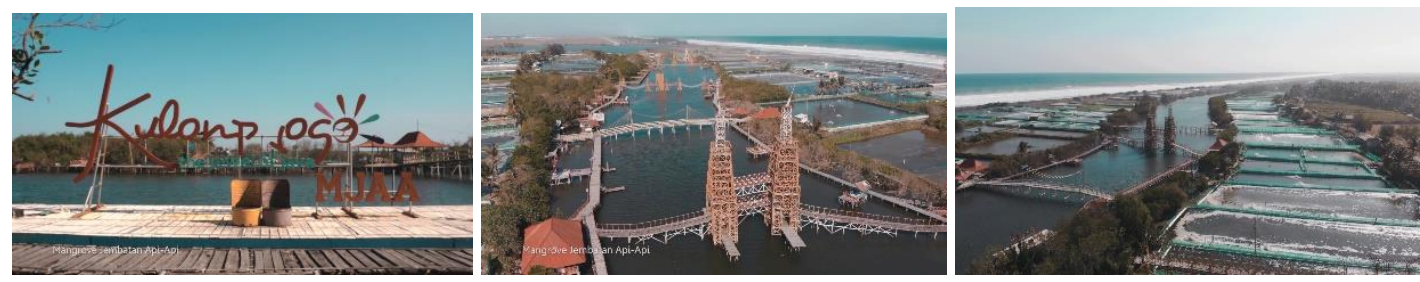

Gambar 16. Scene 13, Mangrove Jembatan Api-api

[Sumber: Dokumentasi Penulis]

Adanya potensi lain yang dimiliki oleh Kulon Progo berupa lautan, salah satunya ialah potensi wisata Mangrove Jembatan Api-api, memperlihatkan keindahan dari tampak depan MJAA dengan background aliran sungai menuju muara laut. Adanya jembatan penghubung di MJAA menjadi sebuah ciri khas yang gambarnya perlu diambil dari tampak atas sehingga mampu menampilkan keindahan MJAA. Oleh sebab itu pada scene 13 menjadi penyambung kelebihan dari Kulon Progo.
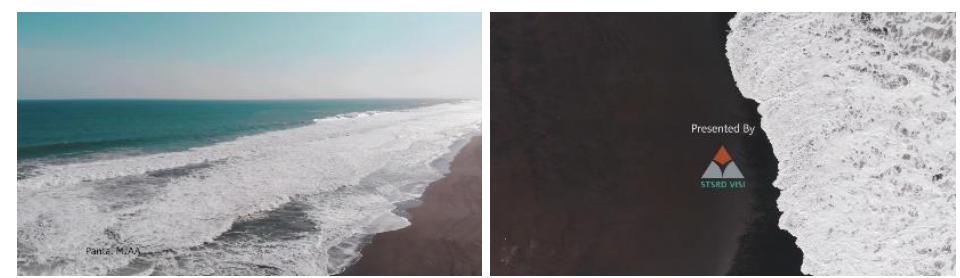

Gambar 17. Scene 14, Pantai MJAA

[Sumber: Dokumentasi Penulis]

Berada di sebelah jembatan MJAA, pantai MJAA menjadi daya tarik yang perlu dikunjungi. Pada scene 14 pantai MJAA akan terlihat sangat indah jika diambil secara extreme long shoot dan tampak atas.
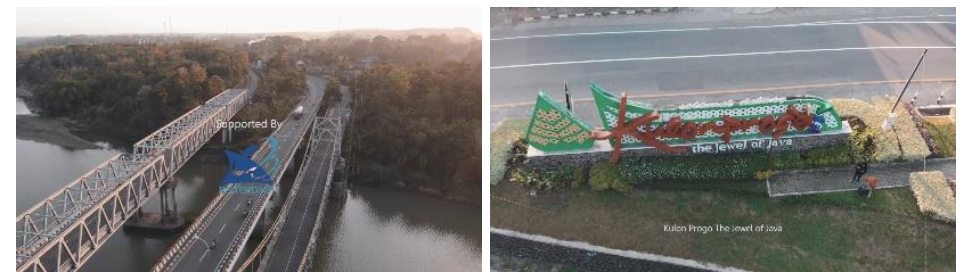

Gambar 18. (kiri) Scene 15, Jembatan Brantan dan (kanan) Scene 16, Tembok display Kabupaten Kulon Progo "The Jewel of Java" [Sumber: Dokumentasi Penulis]

Sebagai bagian akhir dari video perancangan perlu diperlihatkan adanya ciri khas lain yang dimiliki dari Kulon Progo berupa Jembatan Bantar, pada scene 15 menjadi tempat menyajikan Jembatan Bantar dengan extreme long shoot yang melihatkan kemegahan jembatan yang mampu menghubungkan dataran yang terpisah dari Sungai Progo. 
Berada di dekat Jembatan Bantar, pada scene 16 diberikan tampilan tembok display dari Kabupaten Kulon Progo dengan semboyan "The Jewel of Java". Tampilan gambar scene 16 diambil dari tampak atas dan extreme long shoot.

Setelah proses perancangan video selesai dibuat, langkah selanjutnya untuk mengunggah video 4K hasil editing ke kanal Youtube agar dapat diakses oleh para pengguna youtube dalam mencari dan mengetahui keberadaan destinasi wisata Kabupaten Kulon Progo. Video diungguh ke social media Youtube guna mendukung pembuatan citra daerah Kulon Progo di dunia maya terhadap potensi yang dimiliki dan adanya keberadaan bandara baru YIA, salah satu infrastruktur baru yang masih perlu dikenalkan dan menjadi pendukung dalam perjalanan city branding daerah Kulon Progo kedepannya.

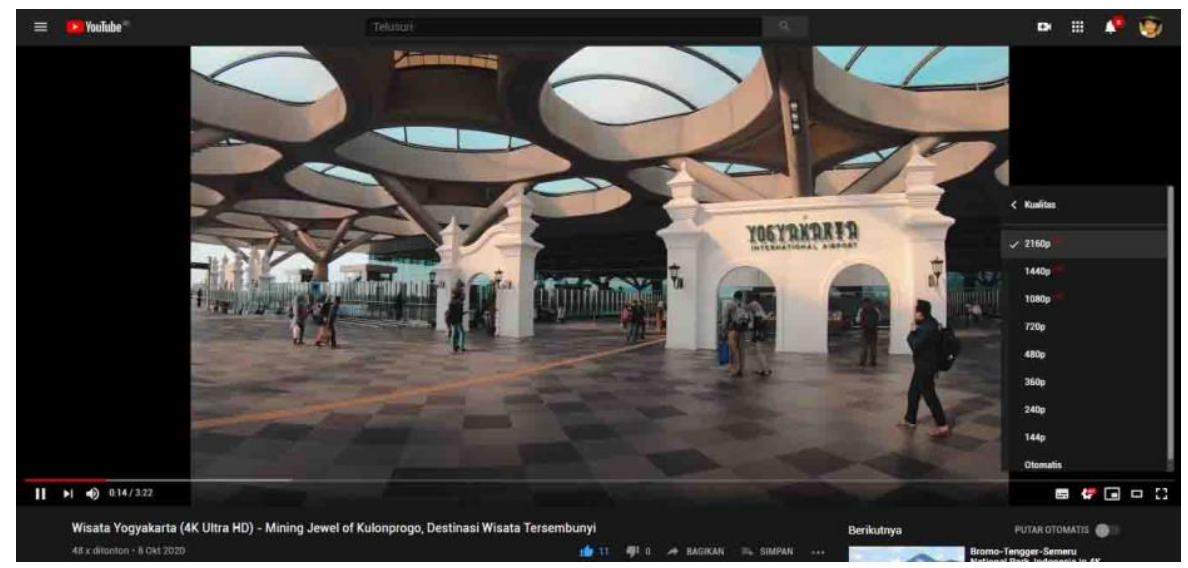

Gambar 20. Video 4K hasil akhir yang diunggah di social media Youtube "Wisata Yogyakarta - Mining Jewel of Kulonprogo"

[Sumber: Dokumentasi Penulis]

Setelah terselesaikan perancangan video $4 \mathrm{~K}$ wisata Kulon Progo, maka langkah selanjutnya ialah tahap evaluasi hasil video terhadap para pengelola destinasi wisata Kulon Progo apakah video $4 \mathrm{~K}$ hasil perancangan ini dapat dijadikan sebagai pembentukan citra dari city branding kulonprogo terhadap kehadiran bandara baru YIA. Hasil dari evaluasi video inipun cukup memuaskan karena jawaban dari keseluruhan pengelola destinasi wisata Kulon Progo merasa penggunaan media video 4K pada kanal Youtube yang diunggah sudah sangat mewakilkan destinasi wisata yang dimiliki, terlebih adanya penyesuaian media video $4 \mathrm{~K}$ oleh para penggunanya saat ini. Adanya kemajuan teknologi komunikasi saat ini dapat menjadi adaptasi media terhadap city branding suatu daerah.

\section{KESIMPULAN}

Terselesaikannya video 4K destinasi wisata Kulon Progo dapat ditarik kesimpulan bahwa adanya sebuah media penyampaian terkini yang lebih dekat dengan penggunanya akan memberikan sebuah dampak yang baik dan maksimal terhadap pengenalan suatu brand ataupun suatu kota, terlebih dalam pengenalan city branding yang kini sudah dapat diakses secara cepat dan dengan jangkauan yang luas. Video 4K inipun menjadi kelebihan yang sangat menarik karena secara tidak langsung dapat mengenalkan dan 
menawarkan berbagai potensi yang dimiliki suatu daerah terhadap pengguna social media yang kini perkembangannya tidak dapat dipisahkan dari kehidupan komunikasi manusia sehari-hari. Berkat adanya pemanfaatan teknologi dan media saat ini seperti Netflix yang menyiarkan tontonan series "Street Foot" makanan Indonesia dengan menampilkan Mbah Satinem seorang penjual jajan pasar langganan mantan presiden soeharto, dapat menjadi sebuah identitas yang meningkatkan sebuah citra (Punky Febi Arifianto, 2020). Melalui video ini, pengguna social media yang melihatnya dapat mengetahui destinasi Kulon Progo dan timbul adanya niat atau keinginan berwisata ke Kulon Progo, terlebih telah tersedianya infrastruktur bandara baru YIA yang akan memudahkan kegiatan berwisata nantinya.

Dengan adanya ikon-ikon wisata yang dikenalkan secara tidak langsung lewat video ini, diharapkan dapat memberikan sebuah rekaman ingatan yang secara otomatis atau sepintas akan mengingat Kabupaten Kulon Progo yang terletak di Provinsi Yogyakarta, memiliki destinasi wisata yang menarik untuk dikunjungi. Sehingga tujuan dari city branding Kulon Progo sebagai destinasi wisata pulau jawa dapat tersimpan secara tidak langsung kepada para penonton dari video ini, karena hakikat dari branding sendiri adalah adanya sebuah ingatan mengenai suatu hal dari sebuah merek. Sama seperti yang dijelaskan oleh Ernest Irwandi (2020) bahwa konstruksi makna city branding dapat diwujudkan dari adanya rangkaian kekhasan suatu wilayah.

\section{DAFTAR PUSTAKA}

Bungin, B. (2011). Penelitian Kualitatif: Komunikasi, Ekonomi, Kebijaksanaan Publik, dan IImu Sosial Lainnya. Jakarta: Kencana.

Cholil, A. M. (2018). 101 Branding Ideas Strategi Jitu Memenangkan Hati Konsumen. Yogyakarta: Quadrant.

Ernest Irwandi, S. S. (2020). Respon Warga Terhadap Perubahan Visual dan Perwujudan Identitas Pemukiman Wonosari Menjadi Kampung Pelangi Semarang. Andharupa, 187-203.

Evandio, A. (2020, October 23). Televisi Pintar Makin Diminati, Ini Alasannya. Retrieved from

Bisnis.com: https://teknologi.bisnis.com/read/20201023/84/1308872/ televisi-pintarmakin-diminati-ini-alasannya

Pemerintah Kabupaten Kulon Progo. (2011, April 13). Branding Kabupaten Kulon progo "The Jewel of Java" Diluncurkan. Retrieved from https://kulonprogokab.go.id/ :https://kulonprogokab.go.id/v31/detil/1480 / branding-kabupaten-kulon-progo-the-jewel-of-java-diluncurkan

Punky Febi Arifianto, N. (2020). Komunikasi Visual Kuliner Banyumas Sebagai Media Pendukung City Branding "Better Banyumas". Andharupa, 63-72.

Sari, G. G. (2014). Analisis Verbal Iklan Smartphone NTT Docomo di Media Televisi Jepang. Japanology, 67-77.

Swasty, W. (2016). Branding Memahami dan Merancang Strategi Merek. Bandung: PT Remaja Rosdakarya.

Uno, H. B., \& Lamatenggo, N. (2011). Teknologi Komunikasi \& Informasi Pembelajaran. Jakarta: Bumi Aksara.

Wesfix, T. (2017). Branding Itu Dipraktekin. Jakarta: PT Grasindo. 